\title{
Study on the Evaluation Standard of Construction Quality for Asphalt Pavement Based on the Intelligent Sensing Aggregate
}

\author{
Chen Zhang $\mathbb{D I D}^{1,2}$ and Yuxin Zheng ${ }^{1}$ \\ ${ }^{1} X i$ 'an Aeronautical University, School of Energy and Architecture, Xi'an 710077, Shaanxi, China \\ ${ }^{2}$ Chang'an University, Key Laboratory for Special Area Highway Engineering of Ministry of Education, Xi'an 710064, \\ Shaanxi, China \\ Correspondence should be addressed to Chen Zhang; zlw19861108@aliyun.com
}

Received 1 April 2021; Revised 29 April 2021; Accepted 6 May 2021; Published 22 May 2021

Academic Editor: Wei Liu

Copyright (c) 2021 Chen Zhang and Yuxin Zheng. This is an open access article distributed under the Creative Commons Attribution License, which permits unrestricted use, distribution, and reproduction in any medium, provided the original work is properly cited.

\begin{abstract}
The traditional evaluation method of construction quality for asphalt pavement has gradually lagged behind the pace of development of the road industry. Big data, Internet of Things (IoT), and intelligent sensing technology have been reflected in the field of road engineering, but these technologies also have technical shortcomings in terms of applicability, durability, real-time performance, and portability in practice. To provide a new method for construction quality evaluation of asphalt pavement, this study developed an intelligent sensing aggregate (ISA) with low cost and high precision based on the 3D printing and Internet of Things (IoT) technology. Based on the laboratory test and field test, the sensing characteristics, high-temperature resistance, and mechanical properties of ISA are analyzed to verify the reliability of ISA. Through the quantitative analysis of ISA perception data, the Driving Perception Index (DPI) is proposed. By analyzing the quantitative correlation between the spatial angle of ISA and the compaction degree, the quantitative correlation between the DPI, International Roughness Index (IRI), and the deflection value, the evaluation standard of construction quality for asphalt pavement is established. The result shows that the best baud rate for ISA is $9600 \mathrm{bps}$, and the corresponding data transmission distance is $350 \mathrm{~m}$. In the range of $6 \mathrm{~m}$, the cars, trucks, trailers, and buses can be perceived by ISA. The maximum operating temperature of ISA is up to $200^{\circ} \mathrm{C}$. Embedding ISA into asphalt mixture has no significant effect on original gradation of asphalt mixture. The established evaluation standard of construction quality for asphalt pavement takes into account the compaction quality, the requirements of bearing capacity, and the driving comfort of asphalt pavement, which is suitable for expressway and first-class highway.
\end{abstract}

\section{Introduction}

Pavement construction is the key part of the whole asphalt pavement engineering. The construction quality of asphalt pavement is closely related to its road performance [1]. If the construction quality of asphalt pavement is poor quality, it is easy to cause pavement cracking and collapse, which not only has a great impact on traffic safety but also increases the cost of highway operation [2]. Therefore, the evaluation of the construction quality of asphalt pavement has important significance. Some researchers used compaction degree as the control index to evaluate the construction quality of asphalt pavement. Hosseini et al. used the core drilling method to develop a framework for connecting pavement construction quality control indicators to long-term performance at the network level [3]. Zhang et al. determined reasonable detection interval of nonnuclear density gauge PQI, and quantitative evaluation index of density distribution uniformity was also proposed [4]. White evaluated a nonnuclear density gauge (NNDG) as part of an asphalt runway resurfacing project. It was concluded that when the temperature had stabilized and the surface was dry, the nonnuclear density gauge (NNDG) was a reliable replacement for destructive coring for density measurement [5]. Hu examined the possibility of utilizing Compaction Meter Value (CMV) to evaluate the density of different asphalt pavement layers [6]. Georgiou and Loizos performed a parametric analysis and developed an optimized approach 
based on ground-penetrating radar (GPR) for assessing accurately the compaction of surface layers of hot mix asphalt (HMA) pavements [7]. It can be seen that the core drilling method, ground-penetrating radar, and nonnuclear density gauge are mainly used to detect the compaction degree. The core drilling method needs to damage the pavement structure layer, which belongs to the damage detection method, and the operation is complicated. The nonnuclear density gauge method belongs to nondestructive testing, but it needs data calibration through core drilling. The ground-penetrating radar method is high cost, vulnerable to noise wave interference, and difficult to data processing.

Modulus is also one of the important indexes of construction quality evaluation for asphalt pavement. Modulus can directly reflect the bearing capacity of pavement structure and judge the quality of pavement [8]. Lin et al. developed a quality assurance procedure to correct the in situ moduli at different field temperatures to a common reference temperature using a fitting function from experimental data for quality assurance and using master curves from laboratory dynamic modulus tests for quality assurance, which can be used for an assessment of the actual pavement performance [9]. Quansah et al. implemented the traffic back-calculation technique through the use of a dynamic cone penetrometer as the effective tool in the assessment of subsurface conditions and evaluation of the structural capacity of a Coca-Cola factory road in Ghana [10]. Jing et al. collected a total of over 1000 sets of FWD data, more than 120 sets of radar spectra, and 138 cores and utilized them for building a comprehensive performance evaluation system for asphalt pavements [11]. Ikechukwu and Mostafa investigated the performance and causes of distress identified on the existing highway along Eastern Nigeria by conducting a series of dynamic cone penetration (DCP) tests [12]. Prabhu et al. did the functional and structural evaluation by visual observation of the pavement and Benkelman beam deflection (BBD) technique on a village road [13]. It can be seen that the Falling Weight Deflectometer (FWD), Benkelman Beam (BB), and the dynamic cone penetrometer (DCP) are mainly used to test the modulus of asphalt pavement at present. However, the FWD is too large and expensive to be widely used. The BB method is mostly suitable for the inverse calculation of subgrade modulus and road surface modulus, but the measured modulus is the static modulus, which is inconsistent with the modulus under vehicle dynamic load. The DCP method determines the bearing capacity of pavement structure by establishing the correlation between penetration and CBR and calculating the field CBR value through empirical formula, but its reliability is low. It can be seen that the current mainstream methods are based on mechanical calculation, field testing, and laboratory tests to evaluate and quantify the construction quality of asphalt pavement. However, these methods lack real time, the detection data often require complex secondary processing, and the portability, environmental protection, and usability of the test equipment also need to be improved [14].
Intelligent sensing technology is the advanced technology of intelligent manufacturing and the Internet of Things (IoT), which is of great significance. In recent years, intelligent sensor technology has developed rapidly in road engineering. Hasni et al. present a surface sensing approach for the detection of bottom-up cracking in asphalt concrete (AC) pavements. The proposed method was based on the interpretation of compressed data stored in memory cells of a self-powered wireless sensor (SWS) with nonconstant injection rates [15]. Xiang and Wang developed a flexible asphalt-mastic packaged optical fiber sensor for distributed strain monitoring of asphalt pavement [16]. However, the intelligent sensors have high requirements for ambient temperature and cannot work normally in an environment above $80^{\circ} \mathrm{C}$, while the compaction temperature of asphalt pavement is as high as $150^{\circ} \mathrm{C}$. Ji et al. fabricated the self-powered damage detection aggregate (SPA) by encapsulating the piezoelectric vibrator with epoxy resin, prepared by compositing the piezoelectric ceramics (PZT) and polyvinylidene fluoride [17]. However, the piezoelectric materials need special cables, and self-recovery is slow when subjected to sudden vibration or excessive pressure.

In summary, the traditional evaluation method of construction quality for asphalt pavement has gradually lagged behind the pace of development of the road industry. At present, the big data, Internet of Things (IoT), and intelligent sensing technology have been reflected in the field of road engineering, but these technologies also have technical shortcomings in terms of applicability, durability, real-time performance, and portability in practice, which to some extent restricts the promotion of the new technologies and new materials in the road industry. In this context, this study developed an intelligent sensing aggregate (ISA) with a small volume, low cost, and high precision based on the Internet of Things technology. Firstly, the reliability of ISA is evaluated from the aspects of data transmission sensitivity, vehicle perception, high-temperature resistance, and mechanical properties. Then, the evaluation standard of construction quality for asphalt pavement considering the compaction quality, the bearing capacity, and the driving comfort is established based on ISA perception data, which provides a new method for construction quality evaluation of asphalt pavement.

\section{Technical Performance of Raw Materials}

2.1. Angular Sensor. The angle sensor module is selected as the main chip of ISA, and its technical parameters are shown in Table 1.

2.2. Wireless Transmission Module. The wireless transmission module is used for full-duplex wireless transparent transmission of the collected data of the angle sensor, and the technical parameters are shown in Table 2 .

The wireless transmission modules are usually used in pairs, one as a transmitter and the other as a receiver. 
TABLE 1: Technical parameters of angular transducer module.

\begin{tabular}{lc}
\hline Parameters & Index value \\
\hline Size & Length: $15 \mathrm{~mm}$; width: $15 \mathrm{~mm}$; thickness: $2 \mathrm{~mm}$ \\
Supply voltage & $3.3-5 \mathrm{~V}$ \\
Working current & $<10 \mathrm{~mA}$ \\
Communication mode & Serial communication \\
Output data & Triaxial angle \\
\hline
\end{tabular}

TABLE 2: Technical parameters of wireless transmission module.

\begin{tabular}{lc}
\hline Parameters & Index value \\
\hline Size & Length: $15 \mathrm{~mm}$; width: $15 \mathrm{~mm}$; thickness: $2 \mathrm{~mm}$ \\
Transmission distance under open field & $600 \mathrm{~m}$ without package \\
Input voltage & $3.7 \mathrm{~V}$ \\
Working current & $60 \mathrm{~mA}$ (emission) and $40 \mathrm{~mA}(\mathrm{receive})$ \\
The maximum transmit power & $22 \mathrm{dBm}$ \\
Control mode & Serial command \\
\hline
\end{tabular}

2.3. External Packaging Layer. The external packaging layer of ISA was prepared by nylon 6/66 copolymer based on 3D printing technology. The material has excellent heat resistance and mechanical properties [18]. The technical indicators are shown in Table 3.

2.4. Other Materials. The plastic steel soil and high-temperature adhesive tape with a temperature resistance of $350^{\circ} \mathrm{C}$ were used as the internal insulation layer of ISA, as shown in Figure 1. The rechargeable lithium battery module is consisting of the lithium battery and the power control module. The voltage of this module is $3.7 \mathrm{~V}$, and the capacity is $400 \mathrm{~mA}$. The power on and off of the power supply module can be remotely controlled wirelessly. The modules are shown in Figure 2.

\section{Methods}

Based on the $3 \mathrm{D}$ printing and Internet of Things (IoT) Technology, an intelligent sensing aggregate (ISA) with low cost and high precision is developed. Based on the laboratory test and field test, the sensing characteristics, high-temperature resistance, and mechanical properties of ISA are analyzed to verify the reliability of ISA. By establishing the quantitative correlation between the ISA sensing data, the compaction degree, the IRI, and the deflection values, the evaluation standard of construction quality for asphalt pavement which can comprehensively consider the compaction quality, the requirements of bearing capacity, and the driving comfort of asphalt pavement are proposed.

\section{Development of the Intelligent Sensing Aggregate (ISA)}

An intelligent sensing aggregate (ISA) with a particle size of $20 \mathrm{~mm}$ was prepared by using the wireless transmission module, the angle sensor, and the rechargeable lithium battery module. The ISA was packaged with 3D printing technology and high-strength and high-temperature-resistant materials to controlling the shape, ensuring mechanical
TABLE 3: Technical indicators of the nylon 6/66 copolymer.

\begin{tabular}{lcc}
\hline Parameters & Units & Index value \\
\hline Density & $\mathrm{g} / \mathrm{cm}^{3}\left(21.5^{\circ} \mathrm{C}\right)$ & 1.53 \\
Vicat softening temperature & ${ }^{\circ} \mathrm{C}$ & 180 \\
Melting temperature & ${ }^{\circ} \mathrm{C}$ & 190 \\
Young's modulus & $\mathrm{MPa}$ & 2350 \\
Tensile strength & $\mathrm{MPa}$ & 67.2 \\
Elongation at break & $\%$ & 11.8 \\
Flexural modulus & $\mathrm{MPa}$ & 1700 \\
Bending strength & $\mathrm{MPa}$ & 97.4 \\
\hline
\end{tabular}
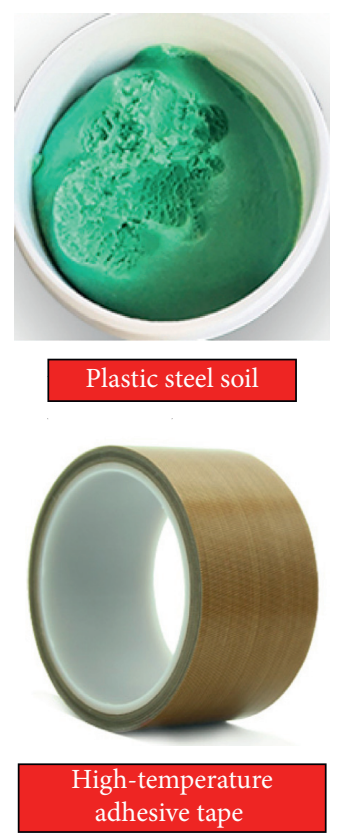

FIGURE 1: Internal insulation layer materials.

strength and signal stability. The preparation process is shown in Figure 3.

The compressive strength of the finished ISA can reach $80 \mathrm{MPa}$. The ISA can obtain the angle data in the three directions of XYZ. The spatial angle was taken as indicators 


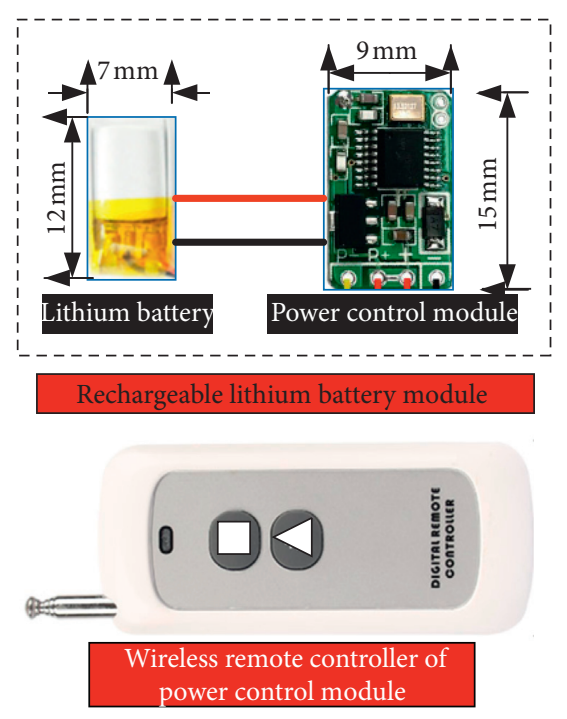

Figure 2: Battery module system.

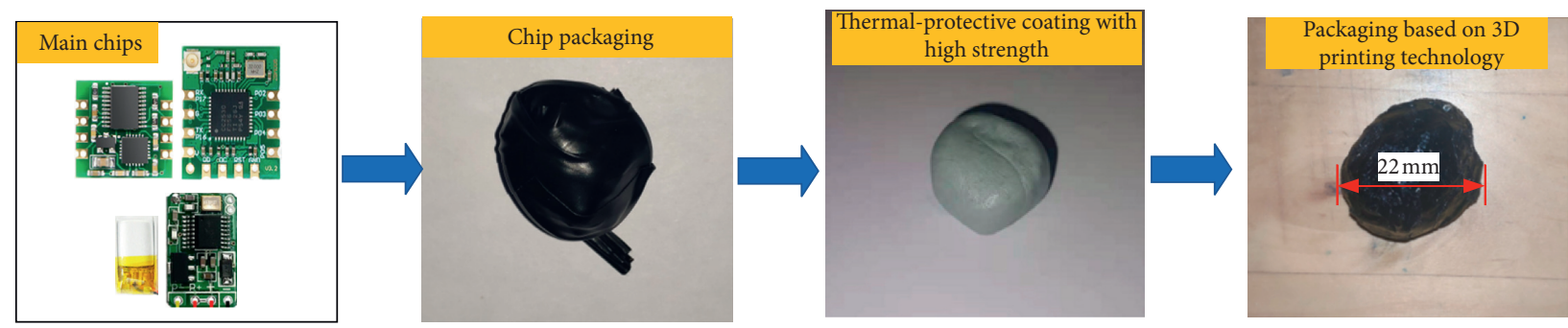

FIGURE 3: The preparation process of ISA.

for analysis in this study. The calculation method is as shown in the following formula:

$$
\Phi=\sqrt{\Phi_{x}^{2}+\Phi_{y}^{2}+\Phi_{z}^{2}}
$$

where $\Phi$ is the spatial angle and the unit is degree $\left(^{\circ}\right) ; \Phi_{x}$ is the attitude angle in the $X$ direction; $\Phi_{y}$ is the attitude angle in the $Y$ direction; and $\Phi_{z}$ is the attitude angle in the $Z$ direction.

This study used Python programming language to develop data acquisition and analysis software of ISA, as shown in Figure 4.

The ISA data acquisition system (IDAS) is developed based on the technology of the Internet of Things (IoT). The size of IDAS is the length of $24 \mathrm{~cm}$, the width of $17 \mathrm{~cm}$, and the height of $10 \mathrm{~cm}$, as shown in Figure 5. The wireless transmission module (receiver) is placed inside the device. The IDAS has a built-in rechargeable battery, which is a portable device. The IDAS can be used for wireless collection and real-time analysis of ISA data.

\section{Reliability Evaluation of ISA}

\subsection{Perception Characteristics Testing of ISA}

5.1.1. Signal Transmission Performance Test. The ISA was buried in asphalt pavement before pavement compaction to test the signal transmission performance under different baud rates (9600 bps, 19200 bps, 38400 bps, 51200 bps, and $115200 \mathrm{bps}$ ). The buried depth is $10 \mathrm{~cm}$, as shown in Figure 6.

The signal strength of ISA can be obtained through the serial port command of the wireless transmission module during the test. The test site is in an open area, and the test results are shown in Table 4.

As shown in Table 4, the ISA conducted normal data transmission in the range of $9600-115,200$ bps of the baud rate. With an increase in the baud rate, the wireless transmission distance and signal strength of the ISA decreased continuously. Considering the accuracy, integrity, and field application requirements of packet transmission, 9600 bps was selected as the transmission baud rate of the ISA, and the corresponding signal transmission distance was $350 \mathrm{~m}$.

5.1.2. Driving Perception Performance Test. When the asphalt pavement is finished, the internal aggregate is in close contact or embedded state, and there is an interaction force between aggregate particles [19]. When an automobile tire contacts the road surface, the aggregate within a certain range around the contact surface is also disturbed due to the force transmission, as shown in Figure 7.

In Figure 6, $L$ is the maximum distance of the disturbed aggregate, which can also be considered to be the perceived distance of ISA. Determining the maximum disturbed 


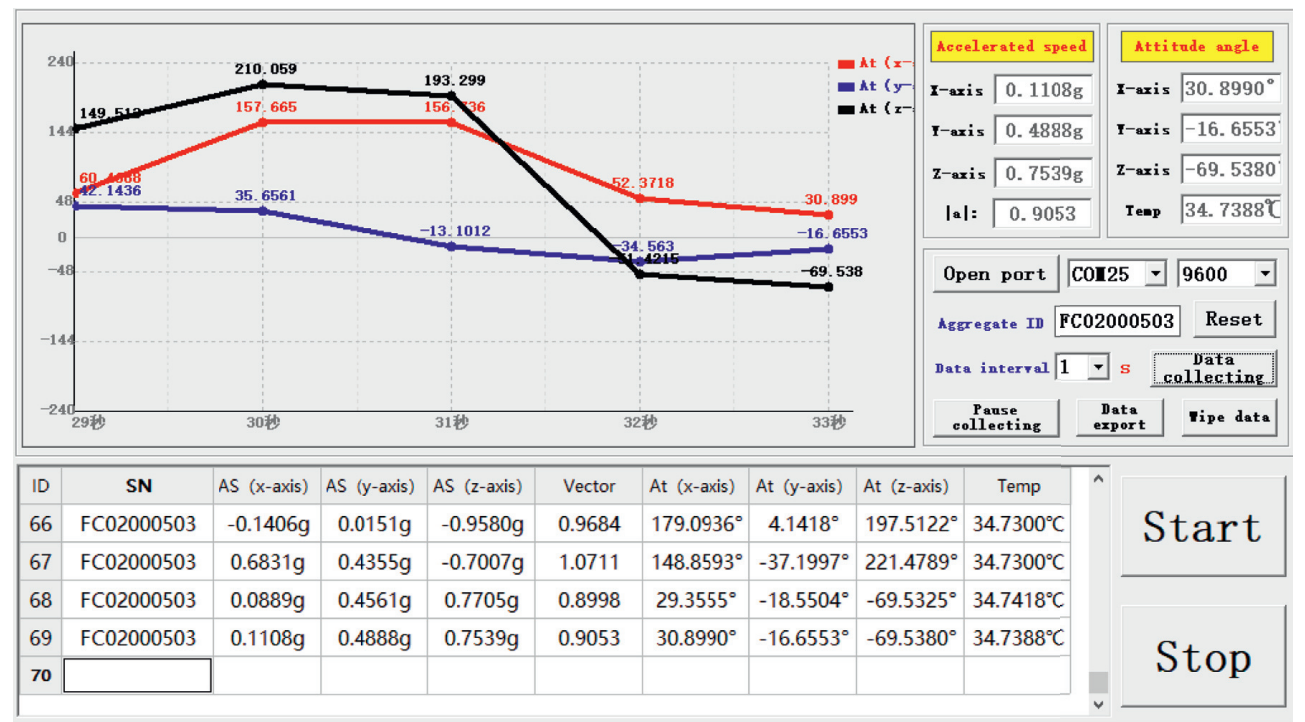

FIgURE 4: The data acquisition and analysis software of ISA.

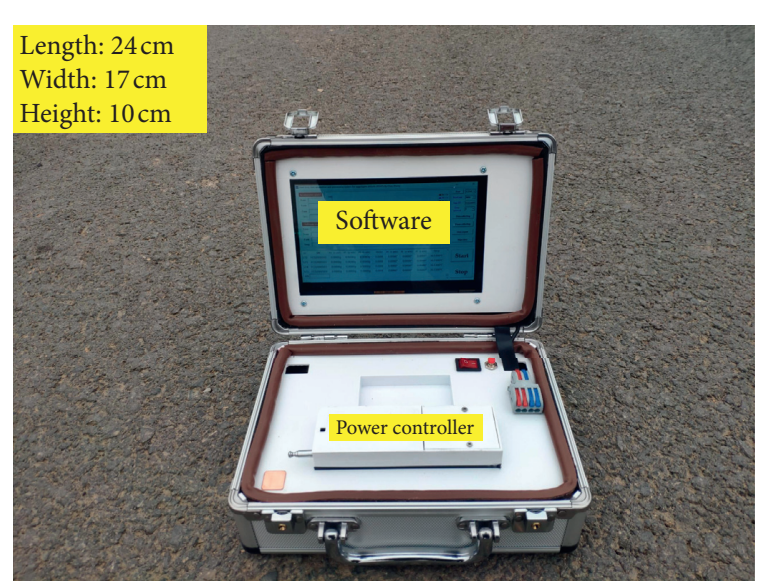

FIgURE 5: The ISA data acquisition system (IDAS).

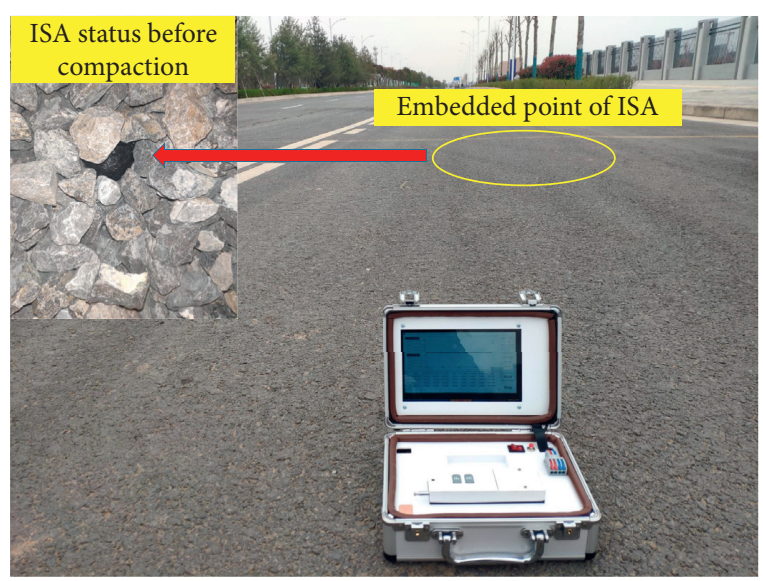

FIGURE 6: Signal transmission performance test of ISA.

distance of the ISA can provide a basis for the layout density of the ISAs on the pavement. The test scheme of the disturbance characteristics for an ISA is shown in Figure 8.
In Figure 8, four common vehicle types, a car, truck, trailer, and bus, were used as the analysis objects, and the laser rangefinder was used to determine the interference distance of various vehicles to the ISA according to the ISA motion data obtained by the IDAS. When the vehicle reached a certain position, if the ISA data fluctuations began to appear, the linear distance from the center of gravity of the vehicle to the ISA was used as the tentatively perceived distance $L_{i}(i=1,2,3,4)$. In the analysis process, 500 sets of data were collected for each vehicle type, and the final results were averaged. The field survey results are shown in Table 5.

From Table 5, the maximum distance for the disturbance of the ISA was $6.2 \mathrm{~m}$. For the convenience of practical applications, the $L$ value was determined to be $6 \mathrm{~m}$ in this paper. In practice, only one ISA was needed to complete the motion data collection for the aggregate within the asphalt mixture in a circular area, with the ISA layout point as the center of the circle and a radius of $6 \mathrm{~m}$.

5.2. High-Temperature Resistance of ISA. The mixing and molding temperature for asphalt mixtures is generally not more than $200^{\circ} \mathrm{C}$ [20]. The ISA was placed in the temperature box, and a high-temperature resistance test with different temperature conditions $\left(25^{\circ} \mathrm{C}, 50^{\circ} \mathrm{C}, 75^{\circ} \mathrm{C}, 100^{\circ} \mathrm{C}\right.$, $125^{\circ} \mathrm{C}, 150^{\circ} \mathrm{C}, 175^{\circ} \mathrm{C}$, and $200^{\circ} \mathrm{C}$ ) was conducted. At the same time, the compressive strength and signal sensitivity of the ISA at each temperature level were tested. The results are shown in Figures 9 and 10.

From Figures 9 and 10, it can be seen that the ISA conducted reliable data transmission up to $200^{\circ} \mathrm{C}$; however, its compressive strength decreased with an increase in temperature until reaching stability. This is because the ISA was composed of a 3D printing layer, plastic steel soil layer, thermal insulation material layer, and chip group from outside to inside. When the temperature reached $125^{\circ} \mathrm{C}$, the $3 \mathrm{D}$ printing layer had been destroyed under the load. However, the plastic steel soil has excellent thermal 
TABLE 4: Test result of wireless transmission performance test.

\begin{tabular}{lcc}
\hline Baud rates $(\mathrm{bps})$ & Wireless transmission distance $(\mathrm{m})$ & Signal strength $(\mathrm{dBm})$ \\
\hline 9600 & 350 & -53.7 \\
19200 & 320 & -57.8 \\
38400 & 290 & -69.2 \\
57600 & 270 & -73.4 \\
115200 & 240 & -78.6 \\
\hline
\end{tabular}

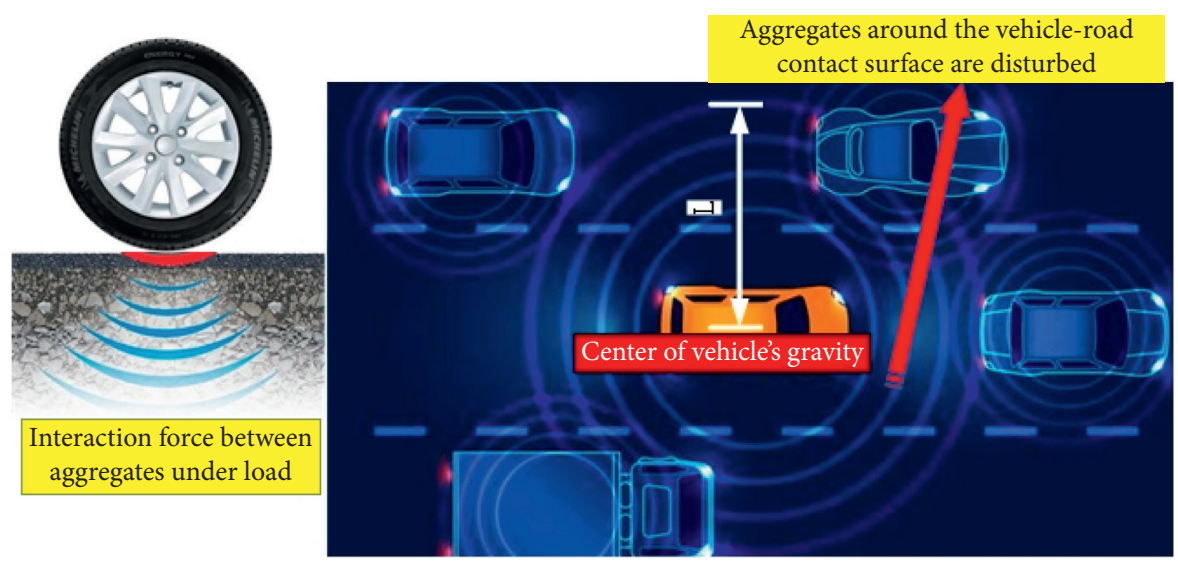

Figure 7: Disturbance characteristics of aggregates.

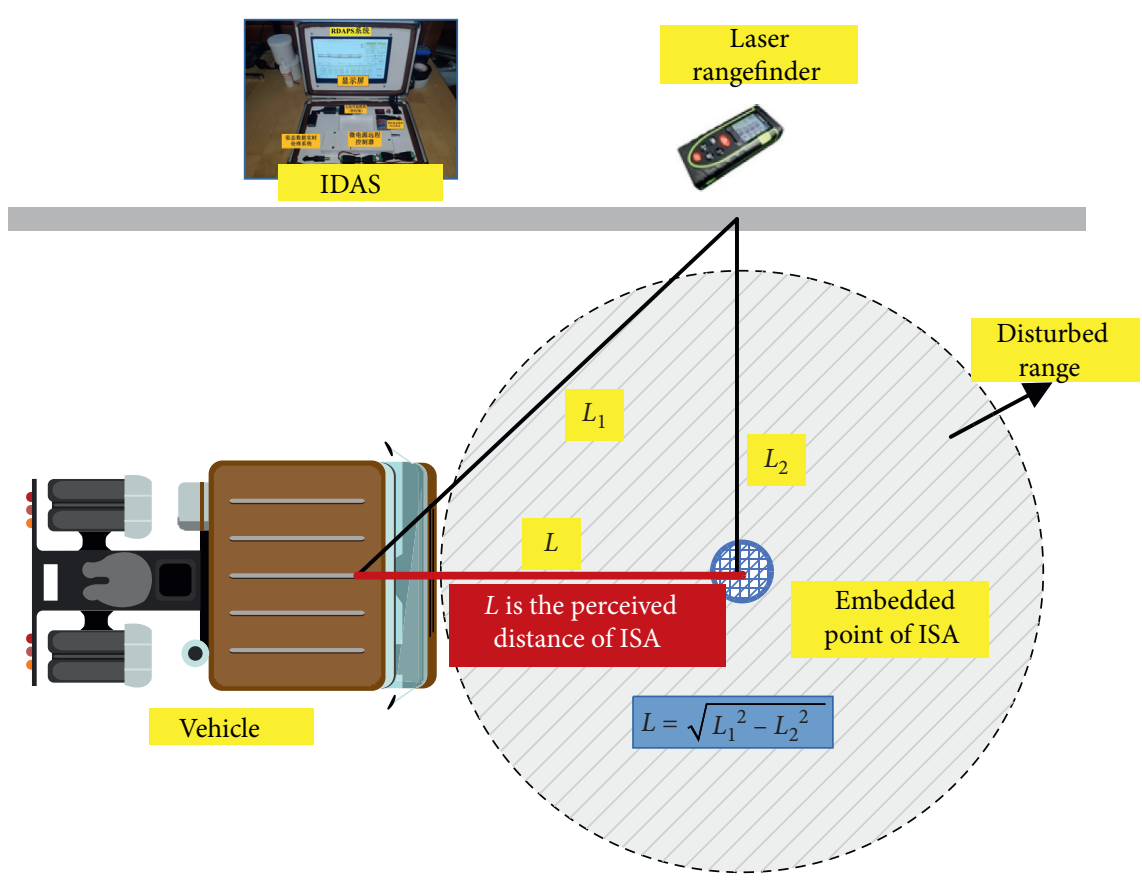

FIgURE 8: Test Scheme for disturbance characteristics of ISA.

TABLE 5: Test results of driving perception performance of ISA.

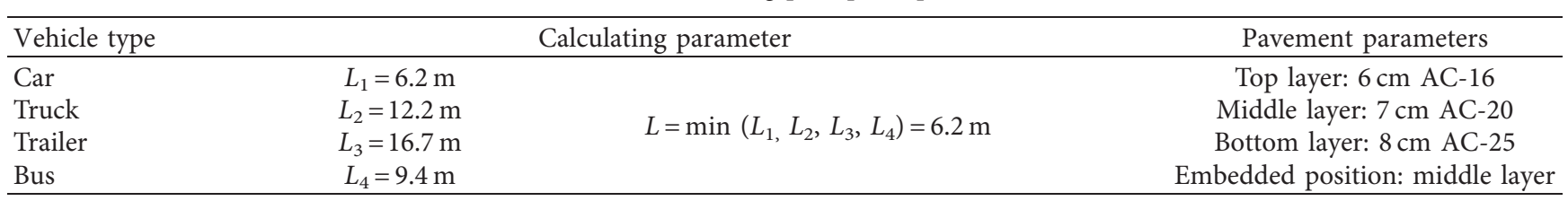




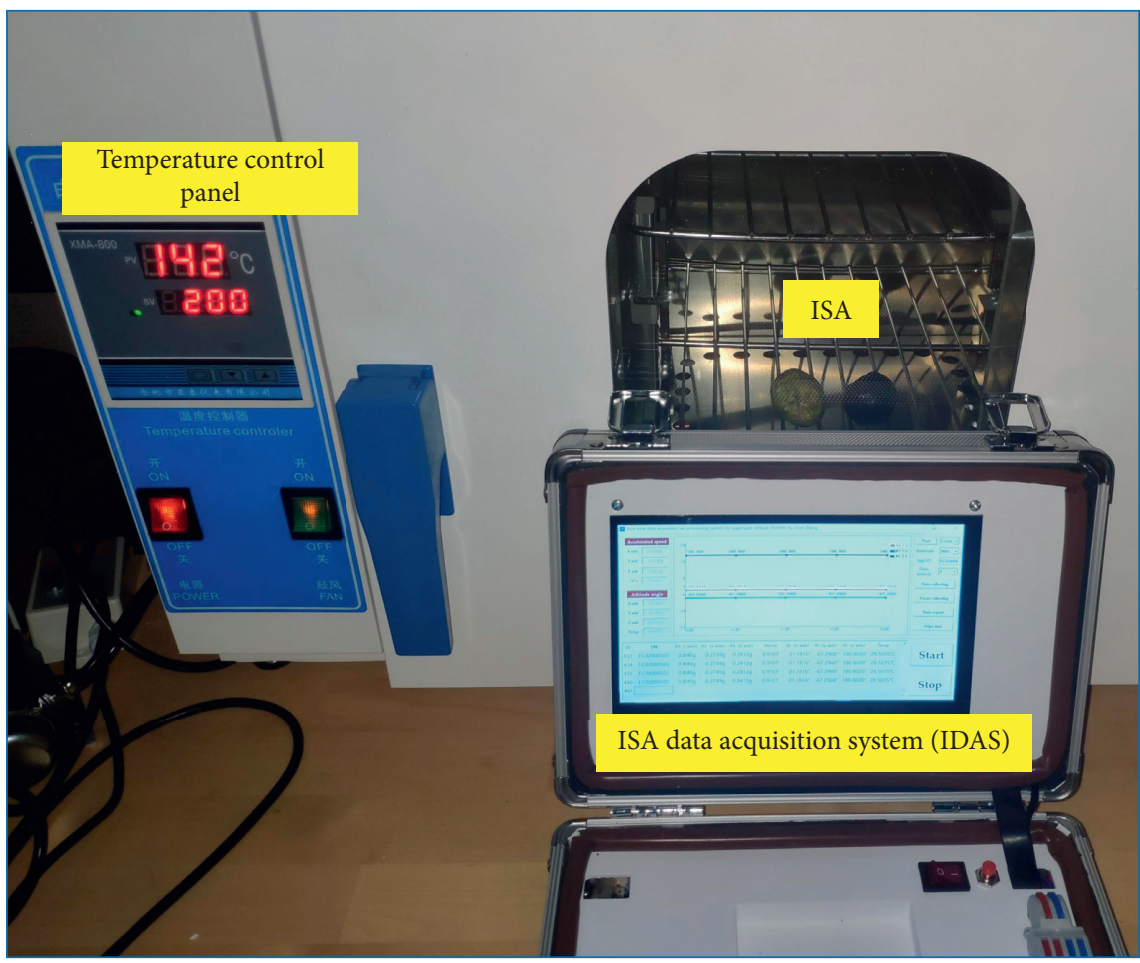

FIGURE 9: High-temperature resistance test of ISA.

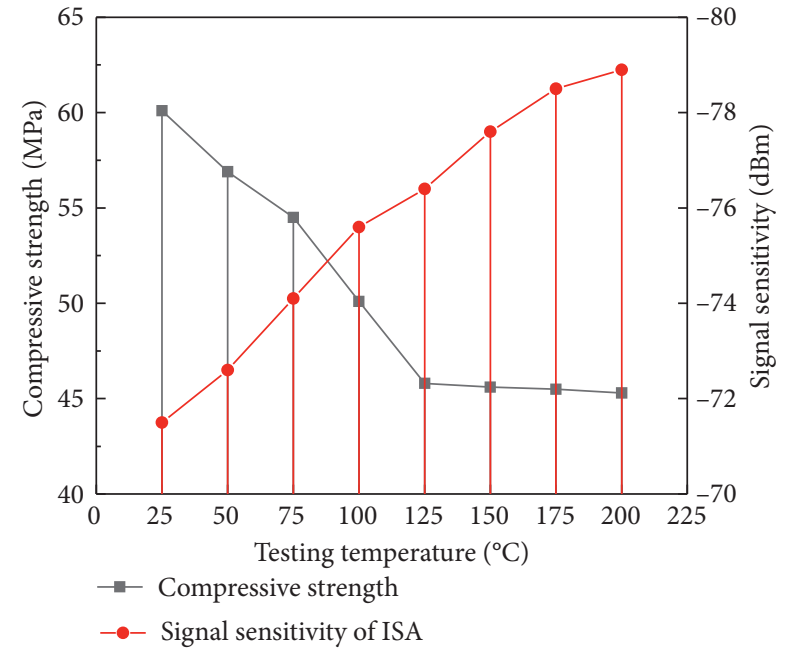

Figure 10: Test results of high-temperature resistance of ISA.

insulation and strength performance, which ensure that the ISA has stable compressive strength and data transmission capabilities.

5.3. Mechanical Properties of the ISA. Based on the laboratory tests, the mechanical properties of the ISA and its mechanical properties in AC-25 gradation asphalt mixtures were studied. The technical performance comparison between the ISA and traditional limestone aggregates is shown in Table 6.

From Table 6, it can be seen that the test values of each index for the ISA were close to that of the limestone aggregate. Through the Superpave Gyratory Compactor (SGC), cylinder specimens of the AC-25 gradation asphalt mixture with a diameter of $100 \mathrm{~mm}$ and height of $150 \mathrm{~mm}$ were prepared by using the limestone aggregate and the oilaggregate ratio of $5.8 \%$. The molding temperature was $175^{\circ} \mathrm{C}$, and the compaction rotation angle was $1^{\circ}$. The ordinary asphalt mixtures and the asphalt mixtures embedded with ISA were respectively formed, and three parallel specimens were prepared. The dynamic modulus tests of the two types of asphalt mixtures were conducted based on the UTM-30 hydraulic servo testing machine, and the results were averaged [21]. The loading frequency was $10 \mathrm{~Hz}$, and the test temperatures were $0^{\circ} \mathrm{C}, 10^{\circ} \mathrm{C}, 20^{\circ} \mathrm{C}, 30^{\circ} \mathrm{C}, 40^{\circ} \mathrm{C}$, and $50^{\circ} \mathrm{C}$. The results are shown in Figure 11.

From Figure 11, it can be seen that the dynamic modulus of the AC-25 gradation asphalt mixture embedded with ISA was slightly lower than that of the ordinary AC-25 gradation asphalt mixture at different temperature levels. The configuration and functionality of ISA are remained intact after the test. Based on the SPSS two-factor variance analysis, the difference analysis of the above test results was conducted, and the results are shown in Table 7.

According to the hypothesis of SPSS two-factor variance analysis, if the $F$-value $<F$-crit and $P>0.05$, there is no significant difference between the two groups of data [22]. It can be seen from Figure 9 and Table 7 that the test values of each index for the ISA were not significantly different from that of the limestone aggregate, which can indicate that the ISA can replace a traditional aggregate to resist external forces and internal load transfer. The dynamic modulus of the AC-25 gradation asphalt mixture embedded with the ISA was not significantly different from that of the ordinary AC- 
TABLE 6: Comparison of physical properties between ISA and traditional limestone aggregate.

\begin{tabular}{lccccc}
\hline Index & Units & Limestone aggregates & ISA & Technical standard & Test methods \\
\hline Crush value & $\%$ & 24.6 & 23.5 & $\leq 28$ & T0316 \\
Abrasion value & $\%$ & 22.4 & 19.6 & $\leq 30$ & T0317 \\
Compressive strength & $\mathrm{MPa}$ & 62.9 & 65.8 & $\geq 50$ & T0616 \\
\hline
\end{tabular}

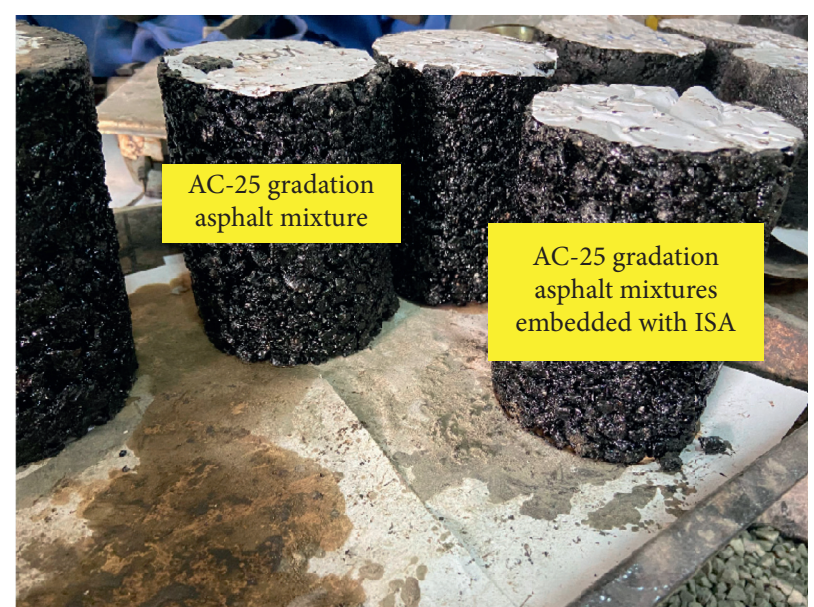

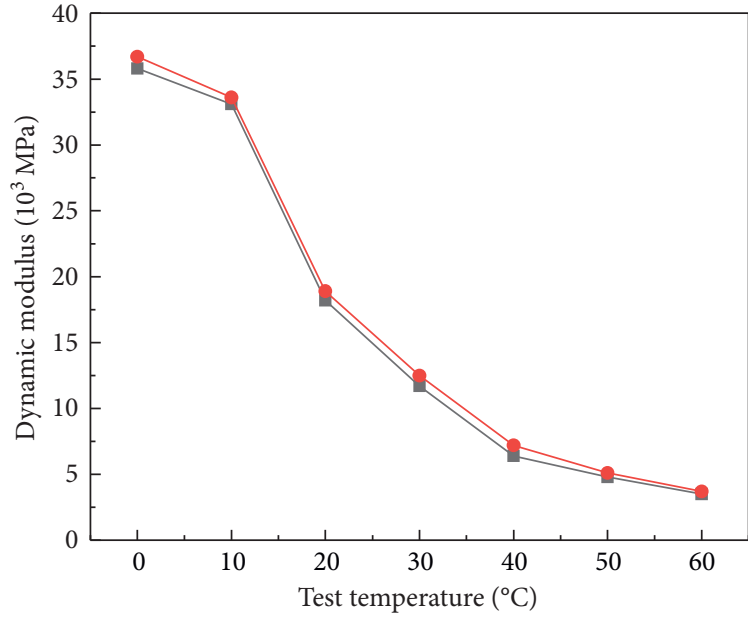

- Asphalt mixtures embedded with ISA

- Ordinary asphalt mixtures

(b)

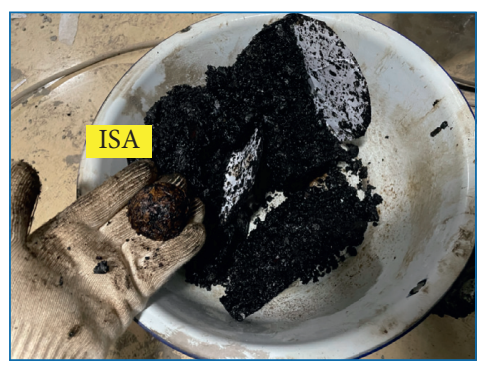

(c)

FIgURE 11: Comparison of dynamic modulus test results. (a) Test specimens. (b) Test result of dynamic modulus. (c) The state of the ISA after test

TABle 7: Difference analysis of test results.

\begin{tabular}{|c|c|c|c|}
\hline Source of variance & $F$-value & $P$ value & F-crit \\
\hline Dynamic modulus of the ordinary asphalt mixtures and the asphalt mixtures embedded with ISA & 7.85 & 0.092 & 10.6 \\
\hline Crush value of ISA and limestone aggregates & 13.2 & 0.083 & 19.7 \\
\hline Abrasion value of ISA and limestone aggregates & 22.5 & 0.076 & 28.3 \\
\hline Compressive strength of ISA and limestone aggregates & 17.4 & 0.105 & 22.6 \\
\hline
\end{tabular}

25 gradation asphalt mixture. It can be inferred that embedding the ISA into an asphalt mixture will not have a significant impact on the original mechanical properties of the mixture.

\subsection{Establishment of Evaluation System of Construction} Quality for Asphalt Pavement Based on ISA. To propose a construction quality evaluation standard of asphalt pavement based on the ISA perception data, the compaction degree, International Roughness Index (IRI), and the deflection value are selected as reference indexes. The compaction degree can reflect the compaction quality of new asphalt pavement, the IRI can reflect the driving comfort of asphalt pavement, and the deflection value can reflect the bearing capacity of asphalt pavement [23]. A new evaluation standard of construction quality for asphalt pavement is proposed in this study. 
5.4.1. Characterization of Compaction Quality Based on ISA. According to the layout schemes in Section 5.1.2, the 25 ISAs were deployed on the test section to be compacted. The test section is 150 meters in total, and the pavement parameters are the same as Table 5. The road compaction scheme is shown in Table 8.

From Table 8 , the additional testing pressure phase is to obtain the final stable value of ISA sensing data. After each compaction, a nuclear density instrument was used to test the compaction degree of the pavement, and the IDAS was used to collect the spatial angle of ISA. The quantitative relationship between the ISA spatial angle and the compaction degree is shown in Figure 12.

From Figure 12(a), for the 25 ISAs observation points, the mean spatial angle of ISA is $82.8^{\circ}$, and the corresponding mean compaction degree is $71.8 \%$ after the completion of the initial pressure stage. In this stage, the movable range of ISA is gradually narrowing, but the ISA is not effectively interlocked in this process, and it is still free. From Figure 12(b), the mean spatial angle of ISA is $14.2^{\circ}$, the corresponding mean compaction degree is $95.9 \%$, and the mean change value of the spatial angle relative to the initial pressure stage is $67.9^{\circ}$ after 6 times repressing. At this time, the compaction degree still does not meet the requirements of the specification which is not less than $98 \%$ for expressway and first-class highway. But the interlocking state between aggregates is gradually formed and the movement of ISA is gradually limited at this stage. From Figure 12(c), the mean spatial angle of ISA is $4.9^{\circ}$, the corresponding mean compaction degree is $98.4 \%$, and the mean change value of the spatial angle relative to the initial pressure stage is $10.1^{\circ}$ after 2 times final pressure. At this time, the compaction degree has met the requirements of the specification for expressway and first-class highway. In order to confirm whether there is room for change in the ISA spatial angle, this study conducted three more road compaction tests during the test compaction stage. From Figure $12(\mathrm{~d})$, the mean spatial angle of ISA is $4.8^{\circ}$, and the mean change value of the spatial angle relative to the final pressure stage is $0.17^{\circ}$ which is not significantly different from a final pressure stage [24]. It can be seen that the spatial angle of ISA is in a stable state at this time. According to the above analysis, $\Phi \leq 5^{\circ}$ after the completion of road compaction as one of the evaluation conditions for the construction quality of asphalt pavement.

5.4.2. The Proposed Driving Perception Index (DPI). The Driving Perception Index (DPI) proposed in this study refers to the driving comfort of drivers based on the ISA perception data, which is used to evaluate the construction quality of asphalt pavement in this study. The better the driver's comfort, the better the construction quality of the pavement. The DPI criteria are determined by analyzing the relationship between DPI, IRI, and deflection value. The IDAS is fixed on the roof of the vehicle for data collected, as shown in Figure 13.

According to the following steps, we collect the data and calculate the DPI value:
(1) Drive $5 \mathrm{~km}$ in a straight line at a speed of $80 \mathrm{~km} / \mathrm{h}$, collect a group of spatial angle data every $0.45 \mathrm{~s}$, and make two trips in the same lane. A total of four groups of data were obtained, with 500 samples in each group

(2) Calculate the absolute value of the difference between two adjacent samples in each group data, and remove the maximum and minimum values

(3) Calculate the mean value of the difference between each group of samples, denoted as $\mathrm{DPI}_{1}, \mathrm{DPI}_{2}, \mathrm{DPI}_{3}$, and $\mathrm{DPI}_{4}$

(4) Take the average value of $\operatorname{DPI}_{i}(i=1,2,3,4)$ as the final DPI, and the unit is the degree $\left(^{\circ}\right)$

The smaller the DPI value is, the higher the driving comfort is, and the better the pavement construction quality is.

5.4.3. Quantitative Correlation between DPI and IRI. The International Roughness Index (IRI) is the most widely used roughness index in the world, and most European countries use IRI as pavement roughness acceptance index. The calculation method of IRI is shown as follows:

$$
\text { IRI }=\frac{1}{L} \int_{0}^{L}\left|Z_{s}-Z_{u}\right| \mathrm{d} x,
$$

where $Z_{s}$ is the absolute displacement of the car body, $Z_{u}$ is the absolute displacement of the tire, $L$ is the distance of driving, and the unit of IRI is $\mathrm{m} / \mathrm{km}$. After the completion of pavement construction, IRI is generally measured by the continuous flatness instrument method. According to the "Inspection and Evaluation Quality Standard for Highway Engineering (JTG F80/1-2017)" and the "Highway Performance Assessment Standards (JTG H20-2018)," the classification standard of IRI for evaluation asphalt concrete surface of the expressway and the first-class highway is shown in Table $9[25,26]$.

The 20 different newly built road sections are selected for field tests, and the test section information is shown in Table 10.

According to the test results, the test values of 12 typical sections are selected for analysis of the correlation between the IRI and DPI, as shown in Figure 14.

From Figure 14, with the increase of IRI, the DPI value also gradually increases until it tends to be stable. When the IRI $\leq 2.3 \mathrm{~m} / \mathrm{km}$, the corresponding DPI value is $5.2^{\circ}$, and the pavement condition is in "excellent" level. When the IRI is from $2.3 \mathrm{~m} / \mathrm{km}$ to $5 \mathrm{~m} / \mathrm{km}$, the DPI increases slowly, with an increase of $84.6 \%$. In this process, the fluctuation of DPI mainly comes from the dynamic contact between the vehicle and the road. When the IRI increases from $5 \mathrm{~m} / \mathrm{km}$ to $10 \mathrm{~m} /$ $\mathrm{km}$, the driving comfort gradually deteriorates, and the DPI increases sharply, with an increase of $350 \%$. This is because the fluctuation of DPI is affected not only by the dynamic contact between the vehicle and the road but also by the bump of the vehicle itself. When the IRI $\geq 10 \mathrm{~m} / \mathrm{km}$, the DPI value tends to be stable, and the road condition is very poor without further testing. In summary, the relationship 
TABle 8: The road compaction scheme.

\begin{tabular}{lccc}
\hline Compaction phase & Compact machinery & Compaction temperature $\left({ }^{\circ} \mathrm{C}\right)$ & Compaction $($ times $)$ \\
\hline Initial pressure & Static roller & 150 & 2 \\
Repressing & Vibratory roller & 135 & 6 \\
Final pressure & Heavy tire roller & 90 & 2 \\
Testing pressure & Static roller & 30 & 3 \\
\hline
\end{tabular}

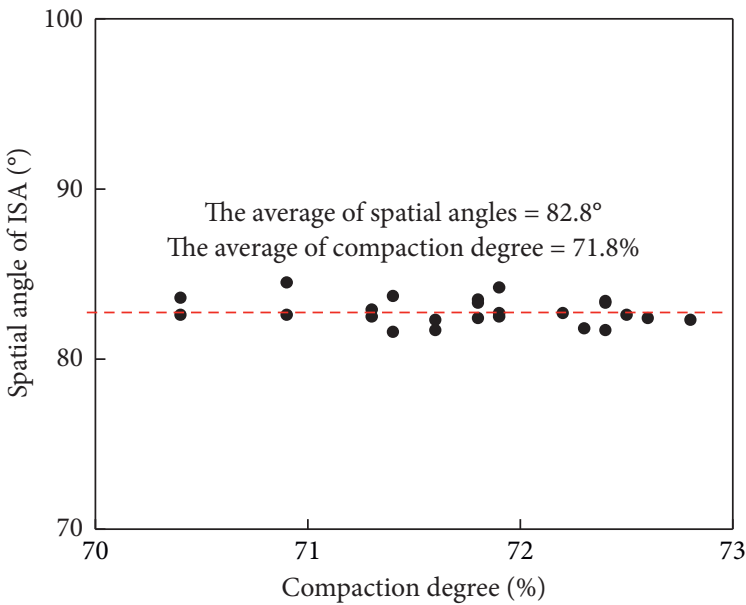

Pavement state after 2 times initial pressure

(a)

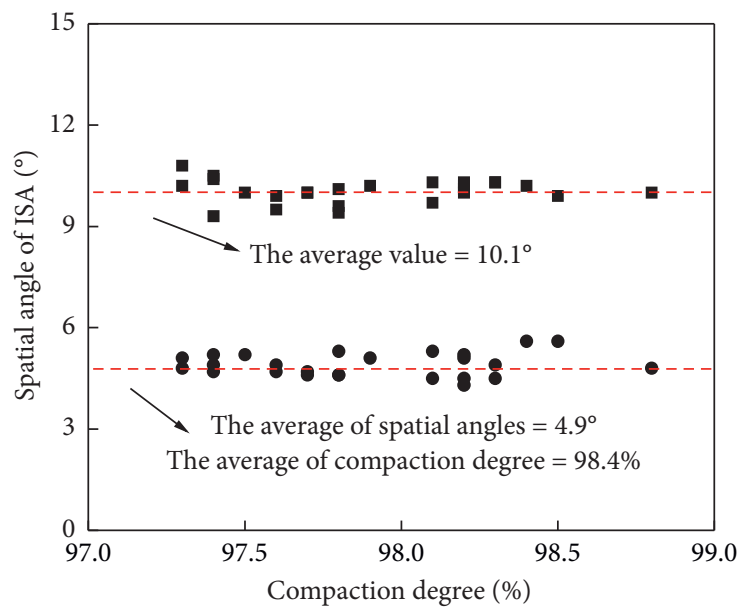

The change value of the spatial angle relative to the repressing stage

- Pavement state after 2 times final pressure

(c)

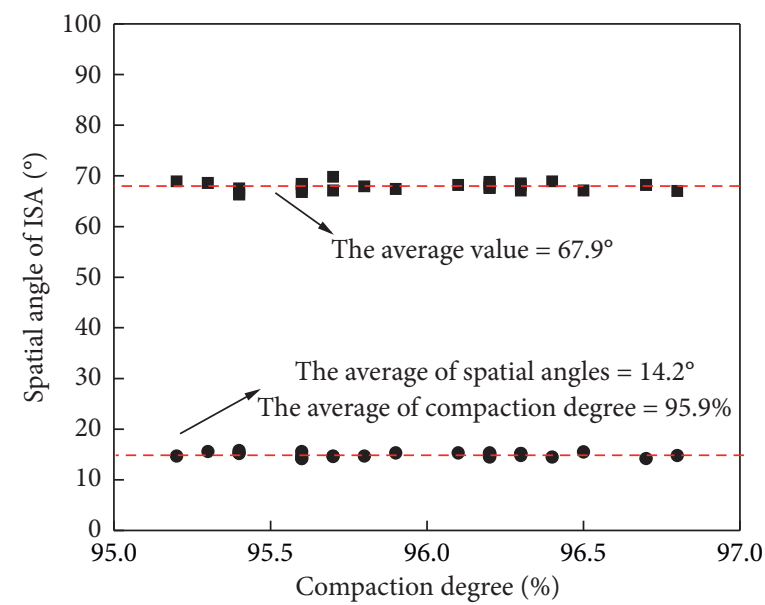

The change value of the spatial angle relative to the intial pressure stage

- Pavement state after 6 times repressing

(b)

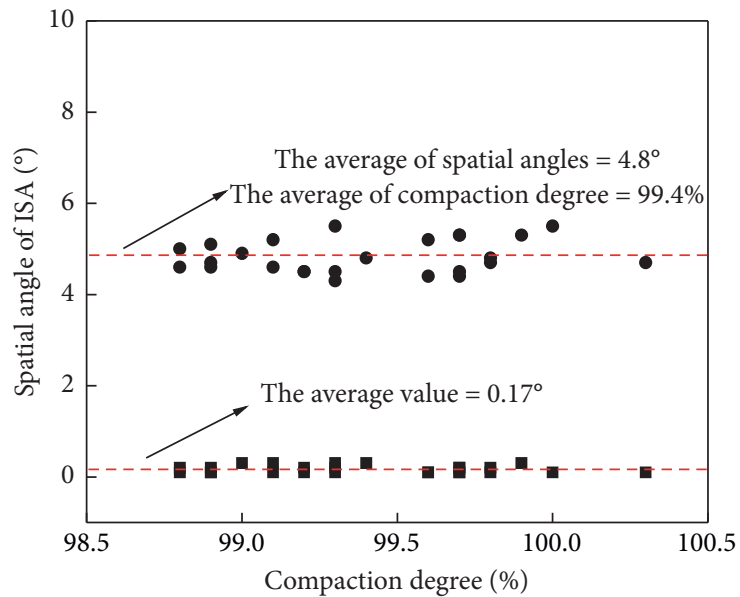

The change value of the spatial angle relative to the final pressure stage

- Pavement state after 3 times testing pressure

(d)

FIGURE 12: The relationship between the ISA spatial angle and the compaction degree. (a) Initial pressure. (b) Repressing. (c) Final pressure. (d) Testing stage.

between DPI and IRI conforms to the actual situation of the project, and the DPI can be used to evaluate the construction quality of asphalt pavement. Referring to the classification standard in Table 8, the evaluation standard of construction quality for asphalt pavement based on DPI is tentatively proposed, as shown in Table 11.
5.4.4. Quantitative Correlation between DPI and Deflection Value. The deflection value is the deformation of the pavement before and after the load acting on the pavement. The deflection index can reflect the bearing capacity of asphalt pavement. The Falling Weight Deflectometer (FWD) is generally used to detect the deflection value of asphalt pavement [27]. 


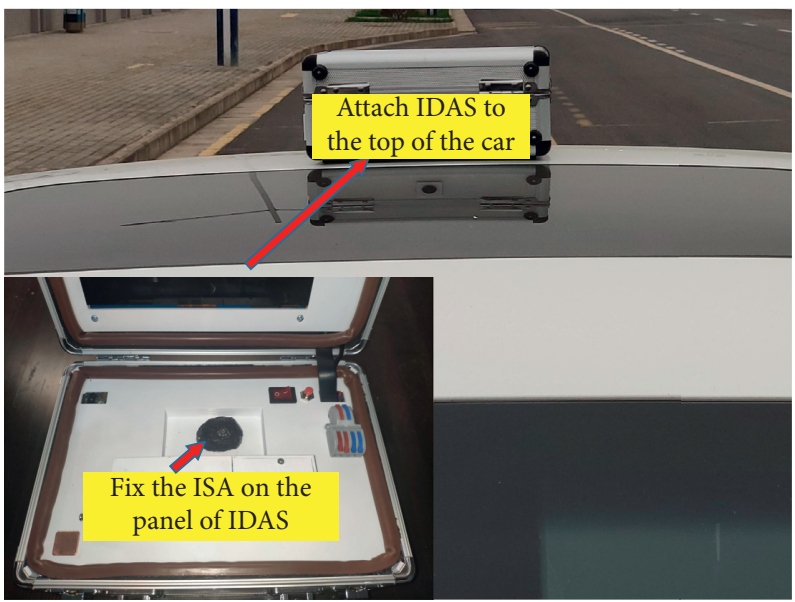

Figure 13: The test scenario of the Driving Perception Index (DPI).

TABle 9: The classification standard of IRI.

\begin{tabular}{lccccc}
\hline Pavement condition & Excellent & Good & Medium & Inferior & Bad \\
\hline Value ranges of IRI $(\mathrm{m} / \mathrm{km})$ & $\leq 2.3$ & $>2.3, \leq 3.5$ & $>3.5, \leq 4.3$ & $>4.3, \leq 5.0$ & $>5.0$ \\
\hline
\end{tabular}

TABLE 10: The test section information.

\begin{tabular}{|c|c|c|c|}
\hline Sections & Length $(\mathrm{km})$ & Pavement structure & Service time \\
\hline 1 & 6 & Top layer: $6 \mathrm{~cm}$ SBS-16 & 1 month \\
\hline 2 & 6 & Middle layer: $7 \mathrm{~cm} \mathrm{AC-20}$ & 2 months \\
\hline 3 & 6 & Bottom layer: $8 \mathrm{~cm} \mathrm{AC-25}$ & 2 months \\
\hline 4 & 6 & Base: $36 \mathrm{~cm}$ cement stabilized macadam & 2 months \\
\hline 5 & 6 & Subbase: $20 \mathrm{~cm}$ graded crushed stone & 2 months \\
\hline 6 & 6 & & 1 month \\
\hline 7 & 6 & & 1 month \\
\hline 8 & 8 & Top layer: $4 \mathrm{~cm} \mathrm{AC-13C}$ & 3 months \\
\hline 9 & 8 & Middle layer: $6 \mathrm{~cm} \mathrm{AC-20}$ & 3 months \\
\hline 10 & 8 & Bottom layer: $7 \mathrm{~cm}$ AC- 25 & 1 month \\
\hline 11 & 8 & Base: $30 \mathrm{~cm}$ cement stabilized macadam & 3 months \\
\hline 12 & 8 & Subbase: $15 \mathrm{~cm}$ cement stabilized macadam & 3 months \\
\hline 13 & 8 & & 1 month \\
\hline 14 & 8 & & 2 months \\
\hline 15 & 10 & Top layer: $5 \mathrm{~cm}$ SMA-13C & 2 months \\
\hline 16 & 10 & Middle layer: $6 \mathrm{~cm}$ AC-20 & 2 months \\
\hline 17 & 10 & Bottom layer: $7 \mathrm{~cm} \mathrm{AC-25}$ & 2 months \\
\hline 18 & 10 & Base: $36 \mathrm{~cm}$ cement stabilized macadam & 3 months \\
\hline 19 & 10 & Subbase: $20 \mathrm{~cm}$ graded crushed stone & 1 month \\
\hline 20 & 10 & & 1 month \\
\hline
\end{tabular}

According to the "Specifications for Design of Highway Asphalt Pavement (JTG D50-2017)," and combined with field experience, the deflection value of the road surface should be less than or equal to $20 / 0.01 \mathrm{~mm}$ during the project acceptance of expressways and first-class highway [28]. The same road sections in Figure 11 are selected for deflection value detection, and the correlation between the deflection value and the DPI is established, as shown in Figure 15.

From Figure 15, with the increase of DPI, the overall deflection value showed an increasing trend. When the DPI is less than or equal to $9.6^{\circ}$, the deflection value rises sharply from 5.9 to 59.6 , with an increase of $910 \%$. When the DPI is greater than $9.6^{\circ}$, the growth of the deflection value significantly slows down. This is because when the DPI is less than or equal to $9.6^{\circ}$, according to the evaluation criteria in Table 10, the pavement condition gradually transits from the "excellent" level to the "poor" level, and the deflection value increases sharply at this stage, which conforms to the actual situation [29]. When the DPI is greater than $9.6^{\circ}$, the investigated pavement condition is "poor" level, the pavement condition of this level is generally caused by 


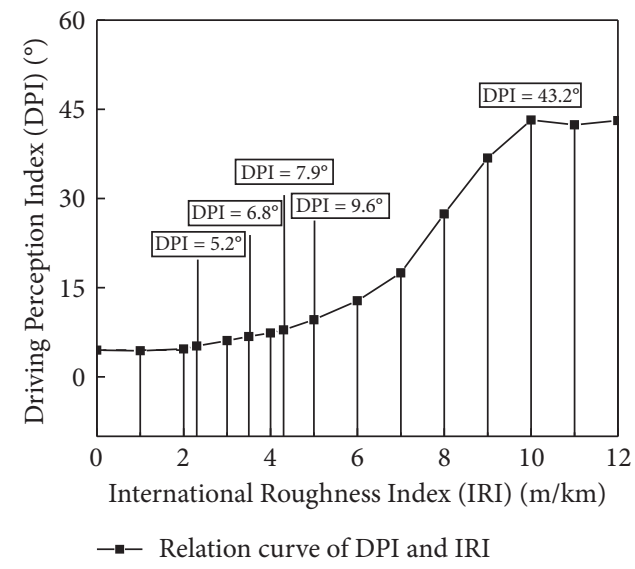

FIGURE 14: The relationship between IRI and DPI.

TABLE 11: Evaluation standard of construction quality for asphalt pavement based on DPI.

\begin{tabular}{lccccc}
\hline Construction quality & Excellent & Good & Medium & Inferior & Bad \\
\hline Value ranges of DPI $\left({ }^{\circ}\right)$ & $\leq 5.2$ & $>5.2, \leq 6.8$ & $>6.8, \leq 7.9$ & $>7.9, \leq 9.6$ & $>9.6$ \\
\hline
\end{tabular}

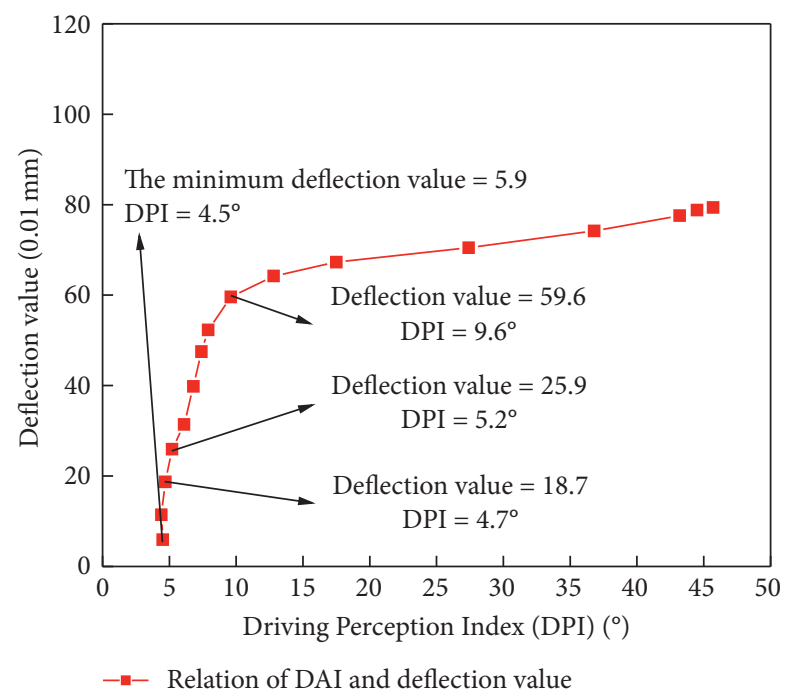

FIgURE 15: The relationship between deflection value and DPI.

insufficient compaction quality or material design defects, and the difference of overall pavement condition at this level is not significant [30]. It is worth noting that when the $\mathrm{DPI}=5.2^{\circ}$, the corresponding deflection value is 25.9 , and the deflection value at this time does not meet the acceptance requirements. But when the DPI $=4.7^{\circ}$, the corresponding deflection value is 18.7 , which meets the acceptance requirements.
In order to make the evaluation standard simultaneously consider the requirements of bearing capacity and driving comfort, the DPI value corresponding to the "excellent" level is corrected in this study, and the final evaluation standard is shown in Table 12.

The evaluation standard of construction quality proposed in this study is applicable to the expressway and firstclass highway. 
TABLE 12: Evaluation standard of construction quality for asphalt pavement based on DPI.

\begin{tabular}{|c|c|c|c|c|c|}
\hline Construction quality & Excellent & Good & Medium & Inferior & $\mathrm{Bad}$ \\
\hline Value ranges of DPI $\left(^{\circ}\right)$ & $\leq 4.7$ & $>4.7, \leq 6.8$ & $>6.8, \leq 7.9$ & $>7.9, \leq 9.6$ & $>9.6$ \\
\hline Matters needing attention & \multicolumn{5}{|c|}{$\begin{array}{l}\text { (1) When the construction quality is "excellent" level, it must also meet the condition of } \Phi \leq 5^{\circ} \text { after } \\
\text { the completion of road compaction } \\
\text { (2) The test mileage of DPI should not be less than } 5 \mathrm{~km} \text { and increased the testing times in the same } \\
\text { lane when the test mileage is less than } 5 \mathrm{~km}\end{array}$} \\
\hline
\end{tabular}

\section{Conclusion}

Based on the Internet of Things technology, a low-cost and high-precision intelligent sensing aggregate (ISA) was developed by using high-strength and high-temperature-resistant materials, wireless transmission module, angular sensor, and rechargeable lithium battery module. Based on the laboratory test and field test, the sensing characteristics, high-temperature resistance, and mechanical properties of ISA were analyzed to verify the reliability of ISA and determine the working conditions of ISA.

The $9600 \mathrm{bps}$ is recommended as the best transmission baud rate of ISA, and the corresponding data transmission distance is $350 \mathrm{~m}$. In the range of $6 \mathrm{~m}$, the cars, trucks, trailers, and buses can be perceived by ISA. The maximum operating temperature of ISA is up to $200^{\circ} \mathrm{C}$. Embedding ISA into asphalt mixture has no significant effect on the original gradation of asphalt mixture.

The spatial angle of ISA $\Phi \leq 5^{\circ}$ after the completion of road compaction as one of the evaluation conditions for the construction quality of asphalt pavement. The Driving Perception Index (DPI) is proposed based on ISA sensing data. With the increase of IRI, the DPI value also increases. When the IRI is $10 \mathrm{~m} / \mathrm{km}$, the DPI value tends to be stable. With the increase of DPI, the overall deflection value showed an increasing trend. When the DPI is less than or equal to $9.6^{\circ}$, the deflection value rises sharply, with a maximum increase of $910 \%$. When the DPI is greater than $9.6^{\circ}$, the growth of the deflection value significantly slows down.

Through the quantitative analysis of ISA perceived data, the evaluation standard of construction quality for asphalt pavement based on the spatial angle of ISA and the DPI value is established. The standard takes into account the compaction quality, the bearing capacity, and the driving comfort requirements of asphalt pavement and is applicable to expressways and first-class highways.

\section{Data Availability}

The data presented in this study are available on request from the corresponding author. The data are not publicly available due to privacy.

\section{Conflicts of Interest}

The authors declare no conflicts of interest.

\section{Authors' Contributions}

Y. Z. investigated the study and validated the data; C. Z. was responsible for methodology and software. All authors have read and agreed to the published version of the manuscript.

\section{Acknowledgments}

This research was funded by the China Postdoctoral Science Foundation (2020M683402), Open Fund of Key Laboratory for Special Area Highway Engineering of Ministry of Education (Chang'an University) (300102210504), the Science and Technology Planning Project of Xi'an (2020KJRC0046), and the Natural Science Basic Research Program of Shaanxi (2021JQ-856).

\section{References}

[1] L. Yao, Q. Dong, J. Jiang, and F. Ni, "Establishment of prediction models of asphalt pavement performance based on a novel data calibration method and neural network," Transportation Research Record: Journal of the Transportation Research Board, vol. 2673, no. 1, pp. 66-82, 2019.

[2] R. Justo-Silva and A. Ferreira, "Pavement maintenance considering traffic accident costs," International Journal of Pavement Research and Technology, vol. 12, pp. 562-573, 2019.

[3] A. Hosseini, A. Faheem, H. Titi, and S. Schwandt, "Evaluation of the long-term performance of flexible pavements with respect to production and construction quality control indicators," Construction and Building Materials, vol. 230, Article ID 116998, 2020.

[4] Z. Zhang, S. Huang, and K. Zhang, "Accurate detection method for compaction uniformity of asphalt pavement," Construction and Building Materials, vol. 145, pp. 88-97, 2017.

[5] G. White, "Evaluation of a non-nuclear density gauge as an alternate to destructive coring for airport asphalt acceptance testing," SN Applied Sciences, vol. 1, no. 921, pp. 1-14, 2019.

[6] W. Hu, B. Huang, X. Shu, and M. Woods, "Utilising intelligent compaction meter values to evaluate construction quality of asphalt pavement layers," Road Materials and Pavement Design, vol. 18, no. 4, pp. 980-991, 2017.

[7] P. Georgiou and A. Loizos, "Parametric optimization of ground penetrating radar approach for assessing asphalt pavement surface layers compaction," Journal of Applied Geophysics, vol. 182, Article ID 104187, 2020.

[8] X. Wang, H. Guo, B. Yang, X. Chang, C. Wan, and Z. Wang, "Aging characteristics of bitumen from different bituminous pavement structures in service," Materials, vol. 12, no. 3, p. 530, 2019.

[9] S. Lin, J. C. Ashlock, and R. C. Williams, "Nondestructive quality assessment of asphalt pavements based on dynamic 
modulus," Construction and Building Materials, vol. 112, pp. 836-847, 2016.

[10] A. Quansah, T. Ntaryamira, and D. Obeng-Atuah, "Evaluation of pavement structural life using dynamic cone penetrometer," International Journal of Pavement Engineering, pp. 1-7, 2018.

[11] C. Jing, J. Zhang, and B. Song, "An innovative evaluation method for performance of in-service asphalt pavement with semi-rigid base," Construction and Building Materials, vol. 235, Article ID 117376, 2020.

[12] A. F. Ikechukwu and M. M. H. Mostafa, "Performance assessment of pavement structure using dynamics cone penetrometer (DCP)," International Journal of Pavement Research and Technology, vol. 13, no. 5, pp. 466-476, 2020.

[13] A. Prabhu, S. P. Arpith, K. K. Vahida, D. Kumar, A. Bhat, and A. Kumar, "Overlay design of flexible pavements using benkelman beam deflection method-A case study," Lecture Notes in Civil Engineering, vol. 99, pp. 475-491, 2021.

[14] J. Yu, X. Zhang, and C. Xiong, "A methodology for evaluating micro-surfacing treatment on asphalt pavement based on grey system models and grey rational degree theory," Construction and Building Materials, vol. 150, pp. 214-226, 2017.

[15] H. Hasni, A. H. Alavi, K. Chatti, and N. Lajnef, "A selfpowered surface sensing approach for detection of bottom-up cracking in asphalt concrete pavements: theoretical/numerical modeling," Construction and Building Materials, vol. 144, pp. 728-746, 2017.

[16] P. Xiang and H. Wang, "Optical fibre-based sensors for distributed strain monitoring of asphalt pavements," International Journal of Pavement Engineering, vol. 19, no. 9, pp. 842-850, 2018.

[17] X. Ji, Y. Hou, Y. Chen, and Y. Zhen, "Fabrication and performance of a self-powered damage-detection aggregate for asphalt pavement," Materials \& Design, vol. 179, Article ID 107890, 2019.

[18] J. Tang, B. Xu, Z. Xi, X. Pan, and L. Zhao, "Controllable crystallization behavior of nylon-6/66 copolymers based on regulating sequence distribution," Industrial \& Engineering Chemistry Research, vol. 57, no. 44, pp. 15008-15019, 2018.

[19] M. Guo, Y. Tan, J. Yu, Y. Hou, and L. Wang, "A direct characterization of interfacial interaction between asphalt binder and mineral fillers by atomic force microscopy," Materials and Structures, vol. 50, no. 2, pp. 1-11, 2017.

[20] T. Al-Mansoori, J. Norambuena-Contreras, and A. Garcia, "Effect of capsule addition and healing temperature on the self-healing potential of asphalt mixtures," Materials and Structures, vol. 51, no. 2, pp. 1-12, 2018.

[21] J. Zhang, Z. Fan, H. Wang et al., "Prediction of dynamic modulus of asphalt mixture using micromechanical method with radial distribution functions," Materials and Structures, vol. 52, no. 2, p. 49, 2019.

[22] M. A. Sanjeev and A. V. Surya, "Two factor theory of motivation and satisfaction: an empirical verification," Annals of Data Science, vol. 3, no. 2, pp. 155-173, 2016.

[23] F. Wang and S. Easa, "Analytical evaluation of ride comfort on asphalt concrete pavements," Journal of Testing and Evaluation, vol. 44, no. 4, pp. 1671-1682, 2016.

[24] J. Zhang, X. Li, W. Ma, and J. Pei, "Characterizing heterogeneity of asphalt mixture based on aggregate particles movements," Iranian Journal of Science and Technology, Transactions of Civil Engineering, vol. 43, no. 1, pp. 81-91, 2018.

[25] Ministry of Transport of the People's Republic of China, Inspection and Evaluation Quality Standard for Highway
Engineering: JTG F80/1-2017, China Communications Press, Beijing, China, 2017.

[26] Ministry of Transport of the People's Republic of China, Highway Performance Assessment Standards: JTG H20-2018, China Communications Press, Beijing, China, 2018.

[27] G. Fu, Y. Zhao, C. Zhou, and W. Liu, "Determination of effective frequency range excited by falling weight deflectometer loading history for asphalt pavement," Construction and Building Materials, vol. 235, Article ID 117792, 2020.

[28] Ministry of Transport of the People's Republic of China, Specifications for Design of Highway Asphalt Pavement: JTG D50-2017, China Communications Press, Beijing, China, 2017.

[29] A. Shen, S. Lin, Y. Guo, T. He, and Z. Lyu, "Relationship between flexural strength and pore structure of pavement concrete under fatigue loads and freeze-thaw interaction in seasonal frozen regions," Construction and Building Materials, vol. 174, pp. 684-692, 2018.

[30] Z. Dong, S. Ye, Y. Gao et al., "Rapid detection methods for asphalt pavement thicknesses and defects by a vehiclemounted ground penetrating radar (GPR) system," Sensors, vol. 16, no. 12, p. 2067, 2016. 